\title{
Switch Over to Alternative Therapy for Diabetes Mellitus -A Life Style Disease
}

\author{
Shweta Singh, Rahul Kumar, Rishi Pal, Narendra Kumar, Dixit RK and Rajendra Nath* \\ Department of Pharmacology \& Therapeutics, K. G'S Medical University, India \\ Submission: June 29, 2015; Published: September 06, 2016 \\ *Corresponding author: Rajendra Nath, Department of Pharmacology \& Therapeutics, K. G’s Medical University, Lucknow, UP, India.
}

\begin{abstract}
Alternative approach to a disease conditions especially life style diseases is an emerging concept in a present scenario of modern medicine. Diabetes mellitus which is one the most dreaded life style disease condition which is spreading as an epidemic across the globe as a large number of individuals who meet the current criteria for diabetes mellitus remain asymptomatic and unaware of having this disorder. Once regarded as a single disease entity, diabetes is now seen as a heterogeneous group of diseases, characterized by a state of chronic hyperglycemia resulting from a diversity of etiologies, environmental and genetic, acting jointly.

Diabetes mellitus has recently been identified by as one of the refractory diseases for which satisfactory treatment is not available in modern allopathic system of medicine. It is therefore evident that alternative approach can be a way out for this iceberg disease. Various alternative approaches such as, Life style modification, Yoga, use of Medicinal plants having multiple beneficial effects .Alternative methods not only take care of most of the metabolic abnormalities associated with diabetes but can also reduce the risk of developing or delay the onset of diabetes mellitus amongst susceptible persons, are becoming a good \& effective alternatives to modern medicines.
\end{abstract}

Keywords: Alternative medicine; Life style diseases; Diabetes mellitus

\section{Bakground}

Diabetes mellitus is a metabolic disorder characterized by hyperglycemia, abnormal metabolism of lipids and proteins along with serious complications affecting various organs like retina, kidney, and nervous system [1]. According to WHO, the incidence of diabetes is increasing day by day [2]. Although conventional therapy is already available for the treatment of diabetes mellitus, it is either associated with adverse effects or development of resistance [3].

Therefore, there is need for alternate therapies which have got better efficacy and fewer side effects. The National Center for Complementary and Alternative Medicine, part of the National Institutes of Health, defines complementary and alternative medicine as a "group of diverse medical and health care systems, practices, and products that are not presently considered to be part of conventional medicine." Complementary medicine is used with conventional therapy, whereas alternative medicine is used instead of conventional medicine [4].

\section{Life Style Modifications}

Modifications in our present life style can be a beginning of alternative approach to any life style diseases especially Diabetes mellitus. It is in the form of: Good eating habits- Less

carbohydrate low fat diet, inclusion of fruits, green vegetables and fibers in the diet. Taking of small multiple meals instead of two or three large meals considering the total calories (Table 1). Regular exercise for more than a hour, five times a week (Table 1). Distressing maneuvers e.g. regular meditation and enjoying hobbies routinely \& many more.

\section{Medical nutrition therapy (MNT) - [5]}

The ADA acknowledges that there is no one-size-fits-all eating pattern for individuals with type 2 diabetes.

Table 1: Showing Physical exercise \& Dietary requirements according to MNT.

\begin{tabular}{|c|c|}
\hline & $\begin{array}{c}\text { A healthy eating pattern to improve overall health, specifically: } \\
\text { o- Achievement and maintenance of body weight }\end{array}$ \\
o- Individualized glycemic, blood pressure, and lipid goals \\
o- Type 2 diabetes prevention \\
- prevent diabetes complications in diabetic patients
\end{tabular}




\section{Current Research in Diabetes \& Obesity Journal}

\begin{tabular}{|c|c|}
\hline 1. Physical activity & $\begin{array}{c}\text { Adults with diabetes } \\
\text { Exercise programs include } \\
\bullet \geq 150 \mathrm{~min} / \text { wk moderate-intensity aerobic activity ( } 50 \%-70 \% \text { max heart rate ) } \\
\text { •Spread over } \geq 3 \text { days /wk with no more than } 2 \text { consecutive days without exercise } \\
\text { - } \text { Reduce sedentary time = break up }>90 \text { minutes spent sitting } \\
\text { •Children with diabetes, pre diabetes } \geq 60 \text { min physical activity/day }\end{array}$ \\
\hline 2. Diet & $\begin{array}{c}\text { 1. Carbohydrates } \\
\text { •Monitor carbohydrate intake to achieve glycemic control } \\
\text { •Carbohydrate intake from veggies, fruits, whole grains, legumes, dairy. } \\
\text { oAvoid other carbohydrate sources, especially those with added fats, sugar, } \\
\text { oSodium. } \\
\text { oSubstitute foods with lower glycemic load for those with higher load } \\
\text { o2. Dietary Fiber \& whole grain } \\
\text { o Fiber: } 25 \text { g/day women; } 38 \text { g/day men (14 g fiber } / 1,000 \text { kcals /day) } \\
\text { o } \geq 50 \% \text { of all grains should be whole grains } \\
\text { Type } 2 \text { diabetes - Do not use carbohydrate sources high in protein to treat to } \\
\text { prevent hypoglycemia . } \\
4 \text {. Fat: } \\
\text { Dietary intake of fats - } \\
\text { - Saturated fat - <10\% of calories } \\
\text { - Cholesterol - < } 300 \text { mg dietary cholesterol/day } \\
\text { - Trans fat --- Limit as much as possible }\end{array}$ \\
\hline 3. Alcohol & $\begin{array}{c}\text { •- Daily moderation } \\
\text { o- Women: } \leq 1 \text { drink/day } \\
\text { o- Men: } \leq 2 \text { drinks/day } \\
\mathrm{o}(1 \text { drink }=12 \text { oz beer, } 5 \text { oz wine, } 1.5 \text { oz distilled spirits })\end{array}$ \\
\hline 4. Sodium & $\begin{array}{c}\text { Reduce to }<2,300 \mathrm{mg} / \text { day } \\
\text { •-Patients with diabetes and hypertension } \\
\text { oConsider goal }<2,300 \mathrm{mg} / \text { day on individual basis }\end{array}$ \\
\hline $\begin{array}{l}\text { 5. Sucrose, Fructose, } \\
\text { Caloric Sweeteners : }\end{array}$ & $\begin{array}{c}\text { •Minimize sucrose intake when substituting for starch } \\
\text { • Free fructose (naturally occurring) } \\
\text { oPotentially better glycemic control vs. sucrose or starch } \\
\text { • Limit/avoid sugar-sweetened beverages } \\
\text { oReduce risk for weight gain, worsening of cardio metabolic profile } \\
\text { •Nonnutritive and hypocaloric sweeteners } \\
\text { oSubstitution for caloric sweeteners may reduce calorie, carbohydrate intake }\end{array}$ \\
\hline
\end{tabular}

MNT is recommended for all individuals with type 1 and type 2 diabetes as part of an overall treatment plan, preferably provided by a registered dietitian skilled in diabetes MNT (Table 1).

\section{Yoga}

Yoga is a traditional exercise regimen that has yielded a statistically significant role in controlling the progression of diabetes mellitus [6-8] .Yoga helps to regulate the body function and psychic processes, thus improving the well-being of the patients [6]. Regular yoga practice can help reduce the level of sugar in the blood, along with lowering blood pressure, keeping your weight in check, reducing the severity of the symptoms and slowing the rate of progression of the disease. It also lessens the possibility of further complications. Stress is one of the major reasons for diabetes. It increases the secretion of glucagon (a 


\section{Current Research in Diabetes \& Obesity Journal}

hormone responsible for increasing blood glucose levels) in the body. The consistent practice of yoga aasanas, pranayam and a few minutes of meditation can help reduce stress in the mind and protect the body from its adverse effects.

This, in turn, reducing the amount of glucagon and improve the action of insulin. Since obesity is a major contributing factor for diabetes, doing yoga to keep your weight in check is the key. There are few Asanas which are especially helpful in controlling Diabetes mellitus [9].

\section{Pranayam}

Breathing in deeply and breathing out helps oxygenate your blood, and improves circulation. It also calms the mind and gives your rattled nerves some much needed rest (Figure 1).

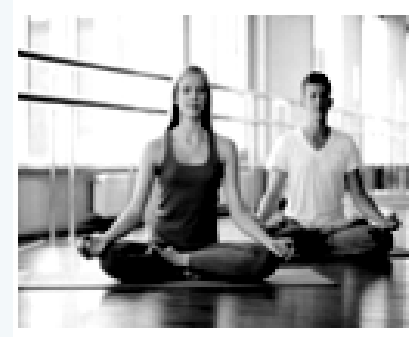

Figure 1: Pranayam.

\section{Setubandhasana}

This pose not only helps keep one's blood pressure \& diabetes in control it also helps to relax the mind, improves digestion and stretches the neck and spine (Figure 2).

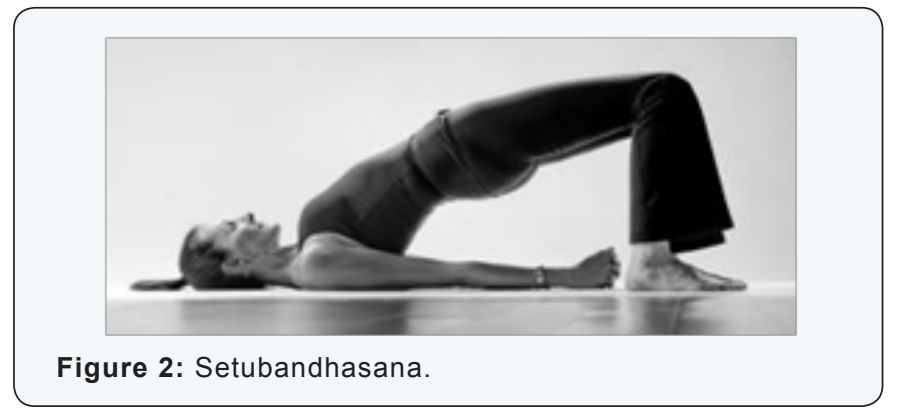

\section{Balasana}

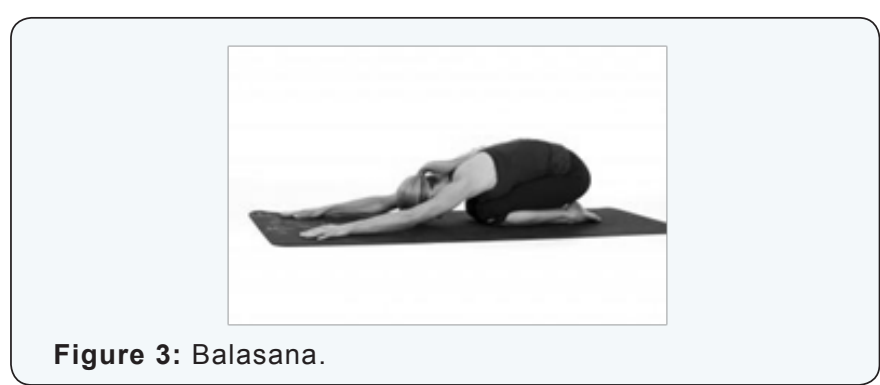

Known quite aptly as the child's pose this is a great stress buster. It gently stretches the hips, thighs and ankles, calms the mind and helps relieve stress and fatigue (Figure 3).

\section{Vajrasana}

This is a simple pose that is great to relax the mind, improve digestion and massages the kanda. According to Ayurvedic principles, kanda is a spot about 12 inches above the anus that is the point of convergence for over 72,000 nerves (Figure 4).

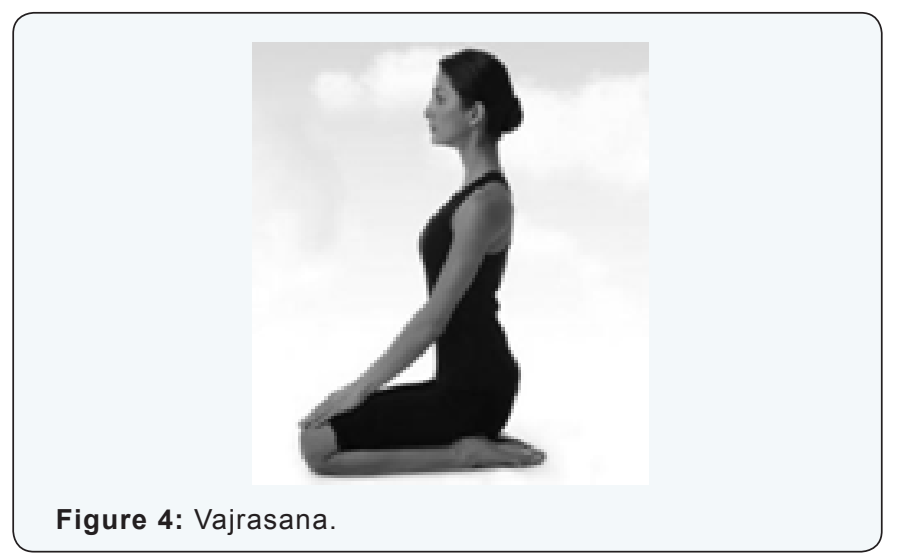

\section{Sarvangasana}

This pose is essentially known for its ability to regulate the working of the thyroid glands. These glands are responsible for the proper functioning of the entire body including the digestive, nervous, reproductive system, regulating metabolism and respiratory system. Apart from that, it nourishes the spine with a good supply of blood and oxygen, helping you beat nervous system disorders, and improving your all round health (Figure 5).

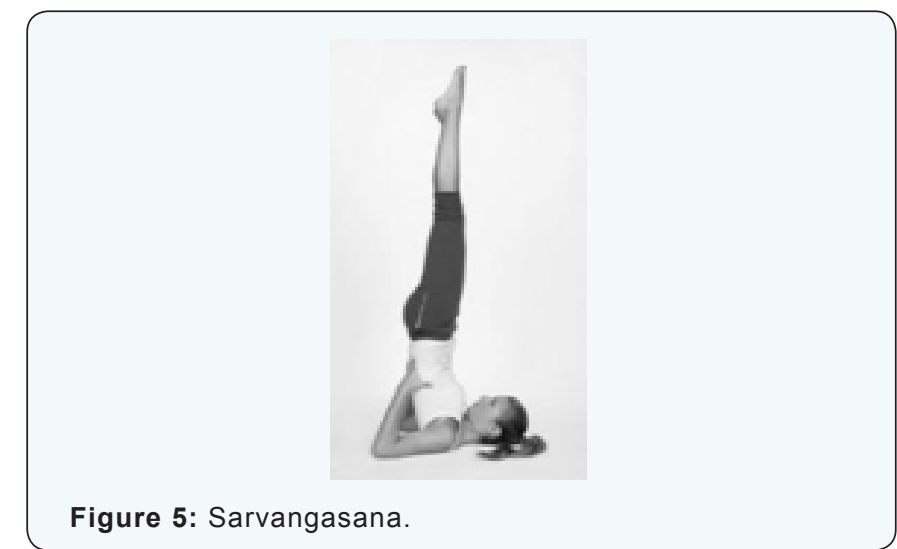

\section{Halasana}

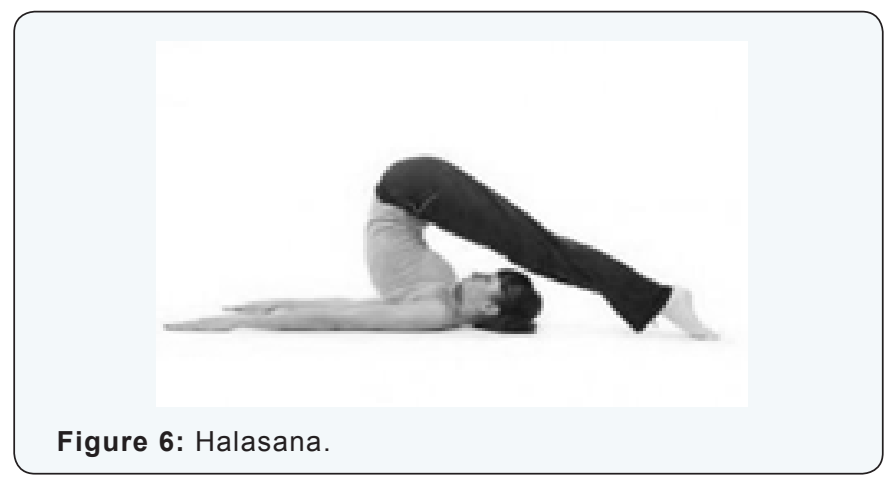




\section{Current Research in Diabetes \& Obesity Journal}

This pose is great for those who sit for long hours and tend to have bad posture. It stimulates the thyroid glands, parathyroid glands, lungs and abdominal organs, therefore helping the blood rush to your head and face, improves digestion and keeps the hormonal levels in check (Figure 6).

\section{Dhanurasana}

This pose is great to strengthen your back and spine, stimulate the reproductive organs, beats stress and fatigue \&control blood sugar (Figure 7).

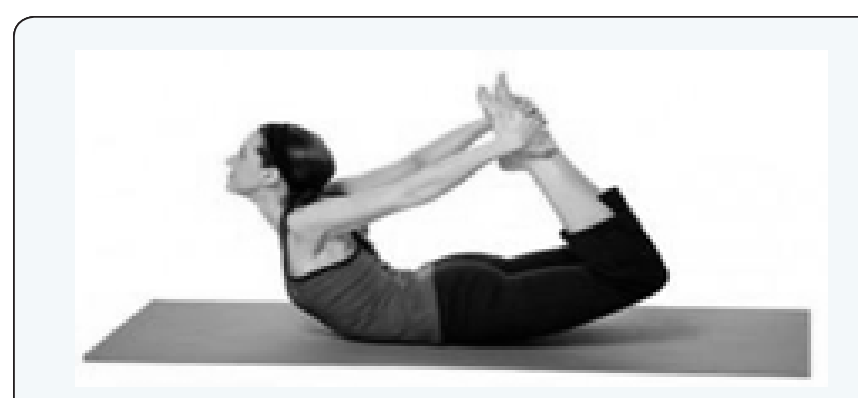

Figure 7: Dhanurasana.

\section{Chakrasana}

This pose is great to stretch the spine and relax the muscles of the back. Moreover it helps relax the mind and make it stress free (Figure 8).

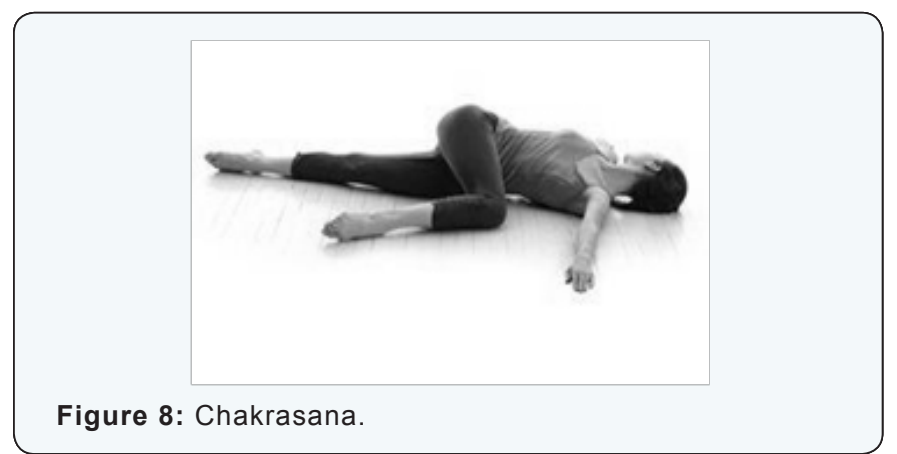

\section{Paschimotasana}

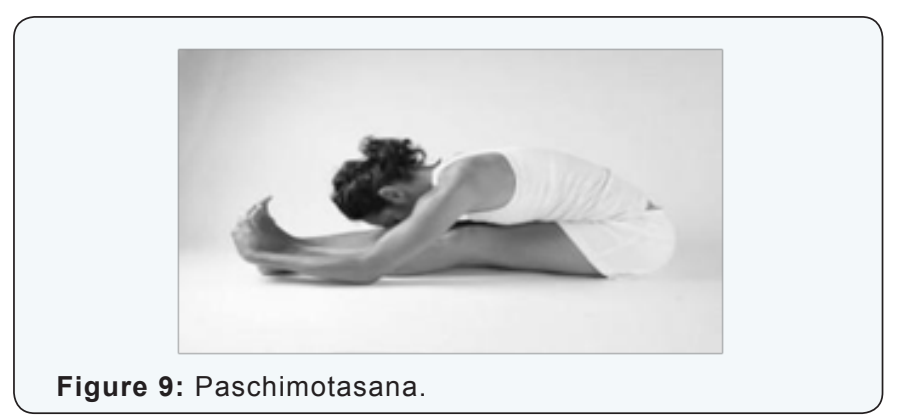

This is a forward bending pose that helps the blood to flow to the face. Apart from that, it helps the stomach function better, strengthens the thigh muscles and relaxes the back and arms and regulates the blood sugar levels (Figure 9).

\section{Ardha Matsyendrasana}

This asana is specifically designed to increase the capacity of your lungs so it can inhale and hold more oxygen. It also loosens up the spine and relieves backaches and discomfort in the back. It also improves the function of pancreatic glands (Figure 10).

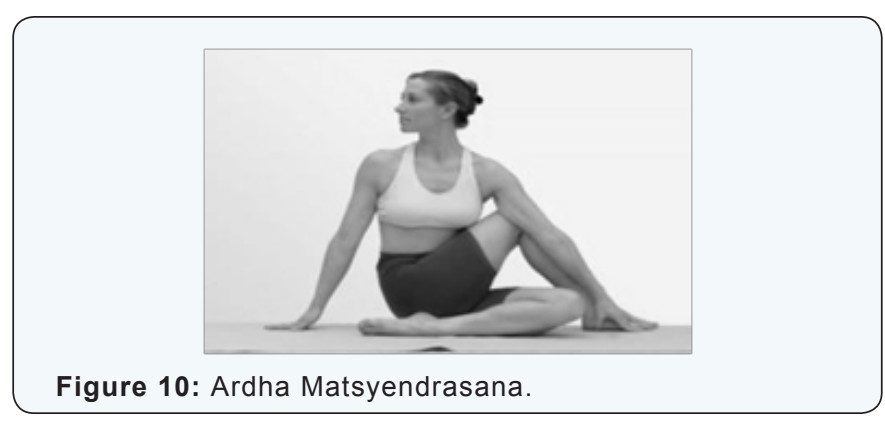

\section{Acupuncture}

Acupuncture helps in the treatment of chronic pain associated with diabetes mellitus. It is a useful tool in the prevention as well as management of complications of the disease. Animal experiments have shown that acupuncture can act on the pancreas to enhance insulin synthesis, increase the number of receptors on target cells, and accelerate the utilization of glucose, resulting in lowering of blood sugar [10]. Studies on physiological mechanisms, both with humans and laboratory animals, indicate that acupuncture may [11]

- $\quad$ Regulate insulin production and blood sugar levels improve the blood lipid profile (dyslipidaemia is common in patients with type- 2 diabetes and may lead to cardiovascular morbidity and mortality).

- Improve blood circulation, thus helping to slow the onset and progression of diabetic circulatory complications.

- $\quad$ Moderate the stress response.

\section{Medicinal Plants}

Nature has been a source of medicinal agents for thousands of years, and an impressive number of modern drugs have been isolated from natural sources, many based on their use in traditional medicine." These plant-based traditional medicine systems continue to play an essential role in health care, with about $80 \%$ of the world's inhabitants relying mainly on traditional medicines for their primary health care. Plant products also have an important role in the health care systems of the remaining $20 \%$, who reside in developed countries. Some plant derived medicines are already in use for various ailments and also a part of modern medicine from long time.

Some herbal plants are proven to provide symptomatic relief and also prevent secondary complications of the diabetes mellitus. The management of type 2 diabetes mellitus is possible with drugs that can lower the blood sugar level on one hand and restore the liver glycogen level on the other hand. In modern system of medicine, there is no drug which is reported to possess both of the properties [12]. Metformin, a less toxic biguanide and potent oral glucose lowering agents, was developed from Galega officinalis and used to treat diabetes $[13,14]$. 


\section{Current Research in Diabetes \& Obesity Journal}

\section{Aegle marmelos}

A species of tree native to India, it is present throughout Southeast Asia as a naturalized species. A significant decrease in liver glycogen of diabetic rats is reversed to almost the normal level by the leaf extract and it also decreases the blood urea and serum cholesterol. A similar effect is seen with insulin treatment and the results indicate that the active principle in A. marmelos leaf extract has similar hypoglycemic activity to insulin treatment [15]. Treatment of streptozotocin-diabetic rats with the leaf extract of $A$. marmelos facilitated the regeneration of damaged pancreas [16].

\section{Allium cepa (onion)}

Allium cepa is known only in cultivation but related wild species occur in Central Asia. Various ether soluble fractions as well as insoluble fractions of dried onion powder show anti-hyperglycemic activity in diabetic rabbits. When diabetic patients were given single oral dose of $50 \mathrm{~g}$ of onion juice, it significantly controlled post-prandial glucose levels [17].

\section{Allium sativum (garlic)}

It is a perennial herb cultivated throughout India. Oral administration of the garlic extract significantly decreases serum glucose, total cholesterol , triglycerides, urea, uric acid, creatinine, AST and ALT levels, while increases serum insulin in diabetic rats but not in normal rats when compared with anti-diabetic drug glibenclamide. The anti-diabetic effect of the extract was more effective than glibenclamide. It is concluded that the plant must be considered as excellent candidate for future studies on diabetes mellitus [18] \& Hyperlipidemia [19].

\section{Andrographis paniculata}

It is an herbaceous plant native to India, Sri Lanka and widely cultivated in southern Asia. Oral

Administration of andrographis significantly increases the activity of SOD and Catalase. Also decreases blood glucose levels due to its antioxidant properties [20].

\section{Azadirachta-indica (Neem)}

Commonly known as Neem. It is a tree native to India, Burma, Bangladesh, Sri Lanka, Malaysia and Pakistan, growing in tropical and semi-tropical regions. A low ( $0.5 \mathrm{~g}$ tid) and high (2g tid) doses of powdered part, aqueous extract and alcoholic extract of A. indica shows significant hypoglycemic activity in high dose and can be successfully combined with oral hypoglycemic agents in type- 2 diabetic patients whose diabetes is not controlled by these agents [21].

\section{Coriandrum sativum}

An annual herb native to southern Europe and North Africa to southwestern Asia. Coriander seed extract (200 mg/kg) significantly increases the activity of the beta cells in comparison with the diabetic control rats and decreases serum glucose in streptozotocin-induced diabetic rats and releases insulin from the beta cells of the pancreas [22]. The extract shows antihyperglycemic, insulin releasing and insulin-like activity [23].

\section{Eclipta alba}

It is widely distributed throughout India, China, Thailand, and Brazil. Oral administration of leaf suspension of E. Alba (2 and 4 $\mathrm{g} / \mathrm{kg}$ body weight) for 60 days results in significant reduction in blood glucose, glycosylated hemoglobin HbA (l) c. Thus, oral administration of E. alba possesses potent antihyperglycemic activity [24].

\section{Emblica officinalis}

Different solvent extracts of E. officinalis acts as $\alpha$-amylase and $\alpha$-glycosidase inhibitor. Significant anti-glycation activity also confirms the therapeutic potential of these extracts against diabetes. Methanol extracts significantly inhibits the oxidation of LDL [25].

\section{Gymnema sylvestre}

In a study by Yadav et al. [26], ethanolic extract of Gymnema displayed hypoglycemic and antihyperglycemic activity in rats which can be attributed to its active compound, dihydroxy gymnemic triacetate.

\section{Ficus religiosa}

Commonly known as Bo or peepal tree, is a large perennial tree that grows throughout India and south-east Asia, especially in the vicinity of temples. The tree is regarded as a blessed tree to both Hindus as well as Buddhists and has got great mythological, spiritual and medicinal significance in Indian indigenous system of medicine like Ayurveda, Unani, Siddha, and Homeopathy (AYUSH).

Some of the ficus species like F. bengalensis bark (bengalanoside), F. racemosa bark (sitoseryl glucosides) and F. carica (fruits) are known to have anti-diabetic properties. Numerous studies have reported Ficus religiosa to exhibit antimicrobial, antifungal, immune-modulator, antioxidant, hypoglycemic, hypolipidemic, anti-helmintics. Studies have shown good anti-diabetic and anti-inflammatory properties which can be used as an alternative therapy in preventing and treating $[27,28]$ this disease.

\section{Momordica charantia}

M. charantia (bitter melon) is commonly known as vegetable insulin. An oral sucrose tolerance test reveals that administration of aqueous extract (AE), methanol fraction (MF) or methanol insoluble fraction (MIF) each significantly suppresses plasma glucose levels at $30 \mathrm{~min}$ as compared with control. Bitter melon suppresses postprandial hyperglycemia by inhibition of $\alpha$-glucosidase activity [29].

\section{Ocimum sanctum (Tulsi)}

It is commonly known as Tulsi. Since ancient times, this plant is known for its medicinal properties. The aqueous extract of leaves shows significant reduction in blood sugar level in both 
normal and alloxan induced diabetic rats [30]. Administration of the ethanolic leaf extract has been reported to lessen the plasma glucose level along with increase in the renal glycogen content, while skeletal muscle and hepatic glycogen levels are decreased in streptozotocin-diabetic rats [31].

\section{Panax ginseng}

The roots are taken orally in the treatment of type II diabetes. Oral administration of P. ginseng root improves insulin sensitivity and may be used as an adjuvant therapy for treating diabetic patients with insulin resistance [32].

\section{Pterocarpus marsupium}

It is widely used in 'Ayurveda' as 'Rasayana' for management of various metabolic disorders. An

Aqueous extract of P. marsupium wood, at an oral dose of $250 \mathrm{mg} / \mathrm{kg}$, shows statistically significant hypoglycemic activity [33]. Marsupin, pterosupin and Iiquiritigenin obtained from this plant show antihyperlipidemic activity [34].

\section{Tinospora cordifolia (Guduchi)}

Commonly known as Guduchi, an herbaceous vine indigenous to the tropical areas of India, Myanmar and Sri Lanka. Oral administration of an aqueous T. cordifolia root extract to alloxan Diabetic rats cause a significant reduction in blood glucose and brain lipids [35].

\section{Trigonella foenum graecum (fenugreek)}

Used both as an herb (the leaves) and as a spice (the seed) and cultivated worldwide as a semiarid crop. Oral administration of 2 and $8 \mathrm{~g} / \mathrm{kg}$ of plant extract produces dose dependent decrease in the blood glucose levels in both normal as well as diabetic rats [36].

\section{Dietary Supplements}

Micronutrients have been investigated as potential preventive and treatment agents for both type 1 and type 2 diabetes $[37,38]$.

\section{Alpha-lipoic acid}

Alpha-lipoic acid is an antioxidant found naturally in foods like spinach, broccoli, and potatoes. The supplement is thought to reduce nerve damage related to diabetes (diabetic neuropathy) and improve the body's ability to use insulin. Some studies support the use of this supplement for neuropathy [39]. While there is some evidence for the benefits of this treatment when taken intravenously, several studies show zero effectiveness in protecting against diabetic macular edema or improve the body's response to insulin, according to the National Center for Complementary and Alternative Medicine (NCCAM).

\section{Chromium}

Chromium facilitates insulin binding and subsequent uptake of glucose into the cell. Supplemental chromium has been shown to decrease fasting glucose level, improve glucose tolerance, lower insulin levels, decrease total cholesterol and triglycerides and increase HDL cholesterol in normal, elderly, and type 2 diabetic subjects [40].

\section{Magnesium}

This mineral is present in many foods, including whole grains, nuts and green, leafy vegetables. A 2011 meta-analysis of diabetes research related to magnesium found that patients with low magnesium levels were more likely to develop diabetes. However, supplementation is not recommended until clinical studies can better assess its effectiveness.

\section{Omega-3 Fatty Acids}

Considered "good" fats, omega-3 fatty acids are those found in salmon (\& other fishes), walnuts, soybeans, and other foods. While supplements may help reduce heart disease risk in as well as reduce triglyceride levels, there is no evidence that they reduce diabetes risk or help patients better manage diabetes. Also, the supplements can interact with medications used to thin the Blood [41].

\section{Vanadium}

Vanadium is a compound found in tiny amounts in plants and animals. Few trials have evaluated the use of oral vanadium supplements in diabetes $[42,43]$.

\section{Conclusion}

As the incidence of diabetes is progressively increasing nowadays, its treatment requires special attention. Some important alternative methods discussed above especially life style modifications \& herbal drugs are the most preferred amongst alternative therapies for the treatment of diabetes mellitus. Herbal medicines are great body balancers that help regulate body functions, can be used to support balance process of our body and offer the nutrients that the body fails to receive due to poor diet or environmental deficiencies in the soil and air. In fact, herbs are always the alternative medicine and primary source. The advantages of using herbal medicines are numerous. They tend to be more effective for long-standing health complaints that don't respond well to traditional medicine. Herbs typically have fewer side effects, and may be safer to use over time. However, further exploration is required to decipher their safety, efficacy and mechanisms of action

\section{References}

1. Qureshi SA, Asad W, Sultana V (2009) the effect of Phyllantus emblica Linn. On type II diabetes, triglycerides and liver specific enzyme. Pak J Nutr 8(2): 125-128.

2. "Diabetes Mellitus", World Health Organization Fact Sheet 1999 No. 138.

3. Zia T, Hasnain SN, Hasan SK (2001) Evaluation of the oral hypoglycemic effect of Trigonella foenum-graecum in normal mice. J Ethanopharmacol 75(2-3): 191-195. 


\section{Current Research in Diabetes \& Obesity Journal}

4. http://www.webmd.com/diabetes/complementary-and-alternativediabetes-treatments?

5. American Diabetes Association (2016) Standards of medical care in diabetes, Diabetes Care 39(suppl 1): S1-S106.

6. Sahay BK (2007) Role of yoga in diabetes. J Assoc Physicians India 55: 121-6.

7. Malhotra V, Singh S, Tandon OP, Sharma SB (2005) the beneficial effect of yoga in diabetes. Nepal Med Coll J 7(2): 145-147.

8. Singh S, Malhotra V, Singh KP, Madhu SV, Tandon OP (2004) Role of yoga in modifying certain cardiovascular functions in type 2 diabetic patients. J Assoc Physicians India 52: 203-206.

9. http://www.thehealthsite.com/diseases-conditions/10-yogaposes-to-keep-diabetes Under-control/.

10. $\mathrm{Hu} \mathrm{H}$ (1995) A review of treatment of diabetes by acupuncture during the past forty years. J Tradit Chin Med 15(2): 145-154.

11. http://www.acupuncture.org.uk/a-to-z-of-conditions/a-to-z-ofconditions/type-2-diabetes.

12. Shrabana C, Tuhin KB, Begum R, Liaquat A, Mosihuzzaman M, et al. (2003) Advanced studies on the hypoglycemic effect of Caesalpinia bonducella F. in type 1 and 2 diabetes in Long Evans rats. J Ethanopharmacol 84(1): 41-46.

13. Bailey CJ, Day C (1989) Traditional plant medicines as treatments for diabetes. Diabetes Care 12(8): 553-564.

14. British Herbal Pharmacopoeia (1979) Keighley, UK. British Herbal Medicine Association.

15. Ponnachan PT, Paulose CS, Panikkar KR (1993) Effect of leaf extract of Aegle marmelos in Diabetic rats. Indian J Exp Biol 31(4): 345-347.

16. Das AV, Padayatti PS, Paulose CS (1996) Effect of leaf extract of Aegle marmelos (L.) Correa ex Roxb. On histological and ultra structural changes in tissues of streptozotocin induced diabetic rats. Indian J Exp Biol 34(4): 341-345.

17. Mathew PT, Augusti KT (1975) Hypoglycemic effects of onion, Allium cepa Linn, on diabetes mellitus a preliminary report. Ind J Physiol Pharmacol 19(4): 213-217.

18. Eidi A, Eidi M, Esmaeili E (2005) Anti diabetic effect of garlic (Allium sativum L.) in normal and streptozotocin-induced diabetic rats. Phytomedicine 13(9-10): 624-629.

19. Akhil Sanghal, Pant KK, Natu SM, Nischal A, Khattri S, et al. (2012) An Experimental Study to evaluate the preventive effect of Zingiber officinale (ginger) on Hypertension \& Hyperlipidemia and its comparison with Allium sativum (garlic) in Rats . Journal of Medicinal Plants Research 6(25): 4231-4238.

20. Dandu AM, Inamdar NM (2009) Evaluation of beneficial effects of antioxidant properties of aqueous leaf extract of Andrographis paniculata in STZ- induced diabetes. Pak J Pharm Sci 22(1): 49-52.

21. Waheed A, Miana GA, Ahmad SI (2006) Clinical investigation of hypoglycemic effect of seeds of Azadirachta-indica in type-2(NIDDM) diabetes mellitus. Pak J Pharm Sci 19(4): 322-325.

22. Eidi M, Eidi A, Saeidi A, Molanaei S, Sadeghipour A (2009) Effect of coriander seed (Coriandrum sativum L.) ethanol extract on insulin release from pancreatic beta cells in streptozotocin-induced diabetic rats. Phytother Res 23(3): 404-406.

23. Gray AM, Flatt PR (1999) Insulin-releasing and insulin-like activity of the traditional anti-diabetic plant Coriandrum sativum (coriander). $\mathrm{Br}$ J Nutr 81(3): 203-209.

24. Ananthi J, Prakasam A, Pugalendi KV (2003) Antihyperglycemic activity of Eclipta alba leaf on alloxan induced diabetic rats. Yale J Biol
Med 76(3): 97-102.

25. Nampoothiri SV, Prathapan A, Cherian OL, Raghu KG, Venugopalan VV, et al. (2010) In vitro antioxidant and inhibitory potential of Tetminalia bellerica and Emblica officinalis fruits against LDL oxidation and key enzymes linked to type 2 diabetes. Food Chem Toxicol 49(1): 125-131.

26. Yadav M, Lavania A, Tomar R, Prasad GB, Jain S, et al. (2010) Complementary and comparative study on hypoglycemic and antihyperglycemic activity of various extracts of Eugenia jambolana seed, Momordica charantia fruits, Gymnema sylvestre, and Trigonella foenum graecum seeds in rats. Appl Biochem Biotechnol 160(8): 2388-2400

27. Rathi Priyanka, Rajendra Nath, Pant KK, Natu SM, Dixit RK, et al. (2013) An Experimental study to evaluate the Hypoglycemic and Anti-inflammatory effect of Ficus religiosa and its comparison with Glibenclamide. Int J Current Research 5(5): 1175-1181.

28. Priyanka Rathi, KK Pant, RK Dixit, Amod Kumar, Rishi Pal, et al. (2016) An Evaluation of the Preventive Role of Ficus religiosa on High Fat Diet and Low Dose Streptozotocin Induced Diabetes Mellitus in Rats. J Diabetes Metab Disord 3(1): 1-5.

29. Uebanso T, Arai H, Taketani Y, Fukaya M, Yamamoto H, et al. (2007) Extracts of Momordica charantia suppress postprandial hyperglycemia in rats. Nutr Sci Vitaminol (Tokyo) 53(6): 482-488.

30. Vats V, Grover JK, Rathi SS (2002) Evaluation of antihyperglycemic and hypoglycemic effect of Trigonella foenum graecum Linn, Ocimum sanctum Linn and Pterocarpus marsupium Linn in normal and alloxanized diabetic rats. J Ethanopharmacol 79(1): 95-100.

31. Vats V, Yadav SP, Grover JK (2004) Ethanolic extract of Ocimum sanctum leaves partially attenuates streptozotocin induced alteration in glycogen content and carbohydrate metabolism in rats. J Ethanopharmacol 90(1): 155-160.

32. Liu TP, Liu IM, Cheng JT (2005) Improvement of insulin resistance by panax ginseng in fructose-rich chow-fed rats. Horm Metab Res 37(3): 146-151.

33. Mukhtar HM, Ansari SH, Ali M, Bhat ZA, Naved T (2005) Effect of aqueous extract of Pterocarpus marsupium wood on alloxan-induced diabetic rats. Pharmazie 60(6): 478-479.

34. Jahromi MA, Ray AB (1993) Antihyperlipidemic effect of flavonoids from Pterocarpus marsupium. J Nat Prod 56(7): 989-994.

35. Dhaliwal KS (1999) Method and composition for treatment of diabetes. US Patent 5886029 A

36. Khosla P, Gupta DD, Nagpal RK (1995) Effect of Trigonella foenum graecum (fenugreek) on blood glucose in normal and diabetic rats. Indian J Physiol Pharmacol 39(2): 173-174.

37. Franz MJ, Bantle JP (1999) American Diabetes Association Guide to Medical Nutrition Therapy for Diabetes. Alexandria Va. American Diabetes Association.

38. Mooradian AD, Failla M, Hoogwerf B, Marynuik M, Wylie-Rosett (1994) Selected vitamins and minerals in diabetes. Diabetes Care 17(5): 464-479.

39. Tankova. T, Cherninkova S, Koev D (2005) Treatment for diabetic mononeuropathy with $\alpha$-lipoic acid. International Journal of Clinical Practice 59(6): 645-650.

40. Baker B (1996) Chromium supplements tied to glucose control. Fam Pract News 15: 5

41. Rachel Nall (2014) medically reviewed by Peggy Pletcher, MS, RD, LD, and CDE Diabetes alternative treatments.

42. Cohen N, Halberstam M, Schilmovich P, Chang CJ, Shamoon H, et al. (1995) Oral vanadyl sulfate improves hepatic and peripheral insulin 


\section{Current Research in Diabetes \& Obesity Journal}

sensitivity in patients with non-insulin dependent diabetes mellitus. J Clin Invest 95(6): 2501-2509.

43. Boden G, Chen X, Ruiz J, van Rossum GD, Turco S (1996) Effects of vanadyl sulfate on carbohydrate and lipid metabolism in patients with noninsulin dependent diabetes mellitus Metabolism 45(9): 11301135. 